\title{
Co-Opetition Between SAP And Oracle: The Effects Of The Partnership And Competition On The Companies' Success
}

Erin M. Troesch, MasterBrand Cabinets, Inc., USA

Paul F. Schikora, Indiana State University, USA

\begin{abstract}
This research paper presents the secondary research findings on the similarities and differences between the strategies of SAP and Oracle, reasons why customers choose one vendor over the other, and how the competition between SAP and Oracle affects their cooperation with each other. This latter effect we refer to as co-opetition. A summary and conclusions will follow a detailed discussion of the aforementioned factors of co-opetition between SAP and Oracle.
\end{abstract}

\section{INTRODUCTION}

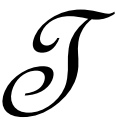

he leading two companies in application software, specifically enterprise resource planning (ERP) systems, have been competing against each other for many years. These companies, SAP and Oracle, continue to battle back and forth to be considered the top enterprise applications vendor in the market. With the current economy, customers are looking for vendors that will provide them with quality, customizable and easy-touse applications at a low, reasonable price. The competition continues to heat up as SAP and Oracle strive to provide better products and services to customers. In addition to the rivalry that many associate with these two companies, SAP offers its customers the ability to use Oracle databases to store the information needed to run an SAP application.

To investigate these current topics dealing with SAP and Oracle as ERP vendors, information was gathered through secondary research. This research consists of several journal and magazine articles in addition to on-line news releases and debates. This research paper presents the secondary research findings on the similarities and differences between the strategies of SAP and Oracle, reasons why customers choose one vendor over the other, and how the competition between SAP and Oracle affects their cooperation with each other. This latter effect we refer to as co-opetition. A summary and conclusions will follow a detailed discussion of the aforementioned factors of co-opetition between SAP and Oracle.

\section{STRATEGIES OF SAP AND ORACLE}

In the past few years, SAP and Oracle have been developing their application strategies in order to provide greater services and become more marketable to customers. SAP's large presence and rapid growth in the market suggest that it has a better strategy than Oracle $\left({ }^{1}\right.$ Wailgum, 2008). Others feel that Oracle's focus on its new Fusion Applications puts its strategy above SAP's ( ${ }^{1}$ Bjorlin, 2008). Several other strategic moves are being heavily debated in the world of ERP systems. The following section includes why some may view SAP's ERP strategy as the best.

\section{SAP's Strategy}

SAP has transitioned to a NetWeaver platform that the company has worked on for many years in order to provide customers with greater service (Greenbaum, 2006). Besides persuading customers to use the relatively new NetWeaver platform and version 6.0 of the SAP ERP system, SAP's plan is to continue expanding into the small and mid-sized business market $\left({ }^{3}\right.$ Bjorlin, 2008). SAP already has a large share of revenue coming from large 
businesses, but more and more small to medium-sized companies are looking for ways to improve their business capabilities and IT systems as well. These companies can benefit from implementing the SAP Business One or Business All-in-One Suite that are both part of SAP's strategy to grow.

Another part of this growth strategy is to focus on partnering with other companies instead of always acquiring them. This includes moving towards a plan of using the solutions developed by third-party companies to better support SAP applications. One major partnership has been developed with Oracle. Customers are able to use Oracle databases and services, supported by Oracle teams, along with their SAP applications (Technology Partners, 2009). Having such a strong partnership with its biggest competitor may allow SAP to appeal to new and existing customers. These customers can gain the advantage of utilizing the vendors' core competencies, SAP's ERP software and Oracle's database capabilities. After all, great customer service and support seem to be two of the greatest factors when trying to gain business in today's market.

Customers looking for service and support may find that SAP is lacking qualified professionals with the knowledge of implementing and training others to use SAP applications ( ${ }^{2}$ Wailgum, 2008). To rid the market of this ongoing idea that SAP lacks knowledgeable candidates for employment, Thomas Wailgum states that SAP is "bringing its message to [students at] colleges and universities and even high schools who might be interested in tech (2008)." Over 700 universities are taking advantage of SAP's program to make students aware of the varying jobs and careers in the ERP market and exposing them to various SAP applications. Providing such education and certification programs gives current SAP executives confidence in the long-term success of the business $\left({ }^{2}\right.$ Wailgum, 2008).

\section{Oracle's Strategy}

Oracle's aggressive strategy differs from SAP's strategic plan in several ways. Researchers believe that the new Fusion Applications will make Oracle's strategy for growth in the market more compelling than any competitor's, including SAP's strategy ( ${ }^{1}$ Wailgum, 2008). Fusion Applications is set to be released sometime in 2010. As of now, it cannot be certain if Oracle's strategy will surpass that of SAP, but several analysts feel that Oracle's vision into the future of the market will be more appealing to customers ( ${ }^{1}$ Wailgum, 2008). Besides releasing new products, Oracle will continue to stick with their strategy of acquiring other companies.

Acquisitions seem to be quite common at Oracle. Its strategy is to get its hands on companies with expertise in specific industry areas $\left({ }^{2}\right.$ Bjorlin, 2008). This way Oracle can provide customers with differing applications and broader capabilities. For example, Oracle recently purchased Sun Microsystems from Microsoft. This acquisition will provide Oracle with better cloud-computing and virtualization capabilities (Chan, 2009). Cloud-computing will enhance Oracle's marketability towards customers looking for SaaS (software as a service). The ongoing plan of acquiring companies that specialize in a certain industry, such as financial services and insurance, gives Oracle the expertise and functionality to attract new users from these industries ( $\left.{ }^{2} \mathrm{Bjorlin}, 2008\right)$.

In addition to competing on increased functionality, Oracle is moving towards a strategy of competing on user-friendliness (deHenry, 2006) and price (Blau, 2005). Oracle continues to look for ways to simplify its architecture and make it user friendly (deHenry, 2006). As the current economic situation affects most companies, ERP vendors' customers may want to look for applications that require less training and are easy to use. Also, those customers may be struggling financially and desire lower priced applications. Several research articles state that Oracle's cost of ownership is less than that of SAP. For example, in 2006, it was believed that "Oracle's average three-year total cost of ownership [was] 48\% lower than SAP's (Westervelt \& Brunelli, 2008)." However, Joshua Greenbaum states that it would be near impossible to prove how much an ERP system will cost a company to implement and maintain because each company has differing objectives and needs (2006). No two companies are similar enough to prove that Oracle is the cheapest ERP vendor. With the lack of strong evidence, it is difficult to know if Oracle's strategy of competing on price/total cost of ownership is a good idea or a deception to new customers. 


\section{Similar Strategic Moves}

As previously discussed, SAP and Oracle have developed different strategies to promote growth for their ERP products. While these two vendors undoubtedly have their differences when it comes to strategic visions, they also have similarities in several key areas. The similar strategic points include enhancing their technology solutions for ERP systems, focusing on customer service and support, and partnering with each other in a professional manner. The first similarity suggests that Oracle and SAP are taking advantage of the newest technologies in marketing their business to customers. Both Oracle and SAP have recently announced that they will offer some of their ERP applications to be downloaded and used on cell phones, particularly Apple's iPhone (Kolakowski, 2009 \& iPod Firmware 3.0, 2009). In this way, SAP and Oracle are keeping up with the ever-changing wants and needs of their customers by providing them with new ways of retrieving and sending information while away from the physical operations of the company.

Customer service, customer support, and application support are very important to both companies. SAP is striving to be proactive about making sure its service and support will remain strong by providing more education and certification programs $\left({ }^{2}\right.$ Wailgum, 2008). Oracle is focusing on developing flexible platforms in order to improve customer service and support (Tillman \& Grady, 2007). The two strategies are also similar when discussing their partnership with each other. As mentioned before, SAP enables its customers the opportunity to use Oracle databases. This alliance allows customers the advantage of running their customizable SAP application software on well-known Oracle databases (Blau, 2005). Customers get the best of both worlds and the vendors are willing to cooperate with each other. SAP and Oracle also partner with other companies in a professional manner to improve their services, applications, and public image to consumers. It seems as though most software vendors, such as SAP, Oracle, Microsoft, IBM, and others are so tightly related that it's hard to avoid working together. For example, analytics specialists Business Objects "are interested in working closer with SAP because [they] have joint clients (Blau, 2005). Companies looking to implement an ERP system for the first time should keep in mind the similarities and differences between the strategies of SAP and Oracle. The vendors' strategies may play a large role in how a company chooses the right vendor for their business needs.

\section{REASONS TO CHOOSE A CERTAIN VENDOR}

Many companies invest in ERP and other technology systems to increase business performance. A company should choose an applications vendor based on its industry-specific needs and required/desired services. Researchers have suggested ways on how to go about choosing an appropriate vendor to match the company's needs. According to R "Ray" Wang and Paul D. Hamerman at Forrester Research (Nov 2008), "a sound vendor selection process consists of four key phases." These phases are illustrated in the Figure 1.

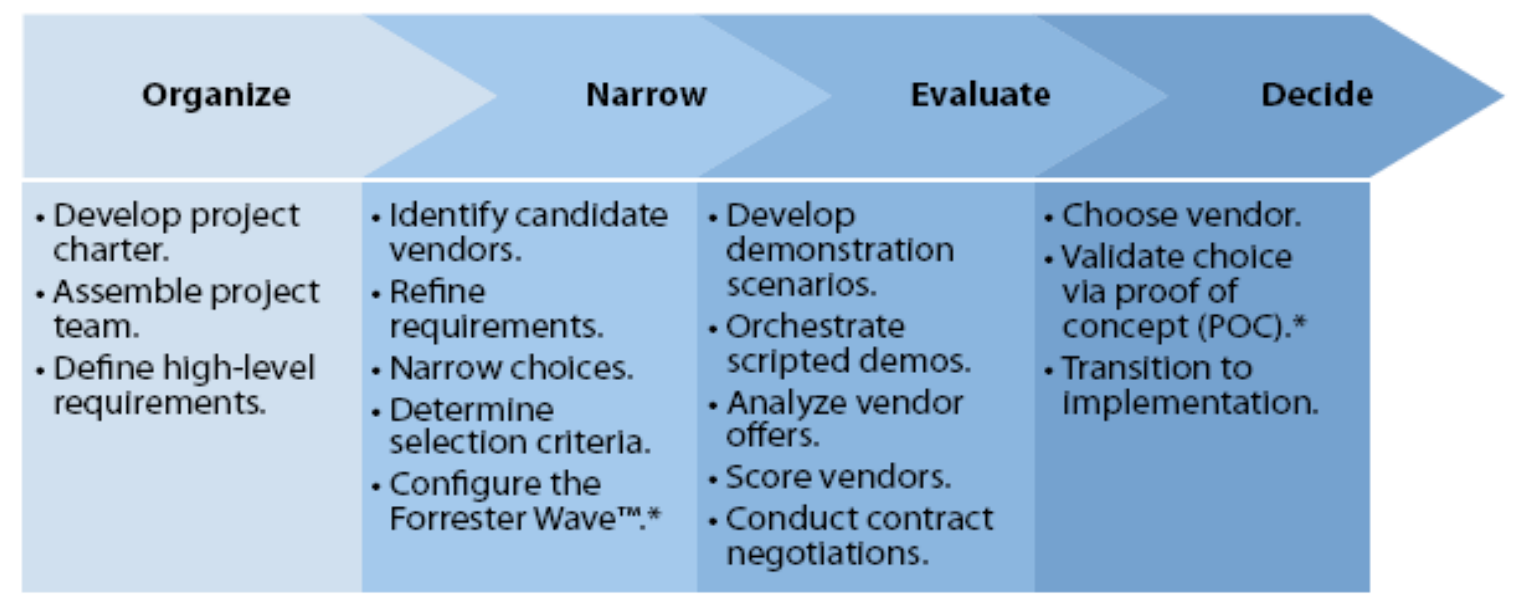

Figure 1: The Vendor Selection Process Overview

Source: Wang, R., \& Hamerman, P.D. (2008, November 11). Topic Overview: Enterprise Apps Vendor Selection. Forrester Research, pp. 2-9 
Figure 1 shows a recommended set of steps that a company should follow in order to choose the right vendor. The first phase is to organize, define, and develop an understanding of what the company hopes to accomplish. Narrowing the field of vendors is the second phase. The asterisk following the final point in this phase suggests that it is an optional step in the process. (The Forrester Wave is a group of reports used to help clients analyze the strong and weak points of possible vendors.) The third phase suggests that companies complete even further research on vendors, such as prices, services, and abilities to meet company needs. During the final phase, a vendor is chosen and the focus moves towards implementation.

SAP and Oracle are by far the largest vendors to consider as companies work their way through the process of choosing an ERP vendor. Together these front runners obtain over half of the ERP market share. As of 2007, Oracle recorded revenue of an estimated $\$ 7$ billion while SAP recorded approximately $\$ 14$ billion in revenue ( ${ }^{2}$ Bjorlin, 2008). While they both offer similar applications packages, customers tend to side with one or the other based on the type of industry, the size of the business, the customer's mission and vision for the future, and other numerous factors. The following section will discuss why some companies have chosen SAP over Oracle and how they went about making such an important decision.

\section{SAP as the Best Vendor}

Several companies, such as Harry \& David, Joerns Healthcare, and Saladino, decided to use SAP as a result of their vendor selection processes. Harry \& David chose SAP because of its capability to provide its growing company with "long-term efficiencies and visibility into its retail and wholesale businesses (SAP AG, 2009)." The mid-sized company believes that SAP, rather than Oracle, will support and fit in well with its vision to offer targeted products to certain stores. Similarly, Joerns Healthcare chose SAP because of the vendor's commitment to research and design ( ${ }^{3}$ Bjorlin, 2009). This commitment matched Joerns Healthcare's overall vision. Saladino, a food distribution company, chose SAP over Oracle due to a higher level of customer service and functionality it received as well as an overall lower cost.

Not only are companies choosing SAP over Oracle based on business-specific factors, but entire industries, specifically the utility and rail industries, feel that SAP is the best to suit their needs. Utilities companies have been using SAP for approximately 10 years. More companies within the industry continue to choose SAP because templates have already been developed by similar companies to ease the implementation process, and SAP's products seem to work well for other utilities companies (Saran, 2008). Improving efficiencies by combining several tasks, such as finance and customer relationship management, make SAP a strong vendor choice, but sometimes the utilities companies are finding themselves having to modify their business processes to match the systems way of doing things. Besides the utility industry, SAP has the ability to run well with railroad companies. Seeing how the ERP system works with railroads currently using SAP is one of the main reasons for others in the same industry to choose it too. In addition, SAP's capability to operate well with other products, such as databases and IBM, led Burlington Northern Santa Fe Railroad to make the decision to side with SAP over Oracle (Franke, 2007).

Most of the aforementioned companies that have chosen SAP indicate that its functionality sets it apart from the main rival, Oracle. In a 2006 debate, Joshua Greenbaum makes a case that says SAP's ability to customize applications before implementation makes it more desirable for certain industries. He also feels that Oracle lacks "deep vertical functionality, a fact acknowledged by the vertical focus of their acquisition and partnering strategy (2006)." This suggests that Oracle is being hurt by acquiring companies while SAP is able to deliver a better vision and proposal for its applications by not relying on other companies as much. While some professionals in the technology industry make strong cases for SAP, there are others who think Oracle has the upper hand when it comes to being the best vendor.

\section{Oracle as the Best Vendor}

New Age Electronics, Welch Foods, Starbucks Coffee, and Restaurant Technologies all decided that Oracle was the better vendor to choose in order to carry out and improve their businesses. These four found Oracle to be easier to use and more flexible. Current Oracle fans, such as Faun deHenry pride Oracle on being easily accessible 
and manageable, no matter whether the user is a fully trained executive or a common administrator (2006). Oracle's ERP system is also said to be easier to implement (deHenry, 2006). This could be the result of SAP focusing more on customizing ERP systems to customer specifications and Oracle focusing on quick deployment of its applications. Most companies tend to choose Oracle if they prefer having flexibility over customization. For example, Restaurant Technologies wanted a flexible platform to keep up with its expected growth rather than customizing applications to meet current needs (Tillman \& Grady, 2007).

Oracle's user-friendliness, flexibility, and smooth implementation process may help prove the case that a positive return on investment will occur faster with Oracle than SAP. Nucleus Research reported that, out of the small and medium-sized businesses using an ERP system, 41\% using SAP received positive returns while an outstanding 93\% using Oracle received positive returns (Tillman \& Grady, 2007). In several instances, customers and Oracle followers feel that the total cost of ownership for an Oracle ERP system is significantly less than SAP, particularly when it comes to training employees. According to Faun deHenry (2006) in making a case for Oracle, "SAP requires on average, four times more internal resources, and companies spend almost twice as much for SAP training." When going through the process of selecting the right vendor, companies may find that their cost to setup, run, and maintain an ERP system from Oracle may vary from their competitors. The cost often depends on how much you rely on the system and what it needs to accomplish for the business. Some companies might not need the advanced capabilities and extensive training for employees that other companies do. Even though there is no stated proof that Oracle costs less than SAP for everyone, several Oracle advocates suggest that Oracle's pricing is more reasonable compared to that of SAP (Westervelt \& Brunelli, 2006).

A more obvious advantage that Oracle has over its competitors is its database business. Oracle has control over much of the market with this business and can now focus on developing additional applications, such as the Fusion Applications. Companies using SAP's ERP system often chose to use Oracle database applications along with it. In doing so, they get the best of both worlds. As Oracle comes out with the new Fusion Applications, those customers may find it beneficial to reevaluate their vendor selection to see if their current ERP solution is still working for them. The competition for ERP customers that exists between Oracle and SAP may have an effect on their partnership with each other. The following section will discuss how the tension between the two ERP vendors affects their ability to cooperate with each other.

\section{COMPETITION AFFECTS COOPERATION}

SAP and Oracle began promoting SAP's R/3 enterprise application suite with the relational databases of Oracle as complimentary products in 1988 (PeopleSoft, 2009). Their cooperation seemed to be going smoothly until Oracle entered the ERP market about 16 years later. Today, the two companies battle for customers in the same markets while continuing to offer products that complement each other; that is, Oracle's databases can still be used with SAP applications. When confronted in an interview about the vendors' competition affecting SAP customers who use Oracle databases, SAP's CEO, Henning Kagermann, stated that both companies "are professional enough to handle co-opetition (Blau, 2005)." Co-opetition is a term he uses in reference to the cooperation and competition that both companies face on a daily basis. Recently, the competition has heated up and Oracle has accused SAP of misusing several customer accounts and documents owned by Oracle (PeopleSoft, 2009). The current battle in the enterprise software market doesn't seem to break down the initial cooperation that began decades ago.

While there is inevitable competition between Oracle and SAP as technology partners, there is nothing to suggest that their partnership in customer support services is under crossfire. Customer service and support are key points in both vendors' strategies. Oracle's support for the databases used by SAP customers is closely linked with SAP support to provide joint customers a wide range of services to enhance the usability of the entire system. On Oracle's side, SAP expertise is required to be able to help customers because of the complex architecture of the SAP ERP system (Oracle support and services for SAP Customers, 2009). The knowledge of Oracle's databases must also exist in order to better confront any issues that arise in that area. 


\section{SUMMARY AND CONCLUSIONS}

To get ahead in the market today, SAP's strategy is to continue pushing its NetWeaver platform, partnering with companies, and investing in more education programs. Oracle is taking a somewhat different approach by focusing on releasing its new Fusion Applications, acquiring companies, and competing on user-friendliness and price. Both vendors also keep in mind the importance of providing excellent support and a wide array of services to their customers. It is difficult to say whether SAP or Oracle has the best strategy because every company is looking for a vendor that closely matches its own vision and strategy.

Many SAP customers are happy with their vendor choice because SAP provides them with visibility, functionality, and the ability to customize applications to meet their business needs. Utility and railroad companies like the fact that SAP has committed itself to working with their specific industries. Oracle fanatics feel that Oracle provides more flexibility than other vendors, is easier to implement and use, and is known to cost less. Oracle's release of its new Fusion Applications could possibly cause some of SAP's customers to switch over to Oracle. Again, it cannot be confidently concluded that Oracle is better than SAP or vice versa because ERP customers have different needs and desires when it comes to choosing the right vendor.

Since Oracle began its partnership with SAP in 1988, the two companies have become increasingly competitive with each other. They're always looking to outdo one another, and Oracle has even sued SAP. Hopefully, both companies can remain professional in order to continue providing customers with SAP ERP systems and Oracle databases as complimentary products. Oracle and SAP must also continue to offer integrated support/service teams for their joint customers. Without a good partnership in providing these services, customers may stop choosing either vendor.

\section{AUTHOR INFORMATION}

Erin M. Troesch is a December 2009 graduate (magna cum laude) of the Scott College of Business at Indiana State University, where she majored in Operations Management and Analysis with a minor in Spanish. In addition to her resident coursework she studied abroad in Chile for a semester. She currently works as a Senior Logistics Specialist with MasterBrand Cabinets in Jasper, Indiana. Her interests include supply chain integration and enterprise resource planning systems.

Paul F. Schikora is Associate Professor of Operations Management in the Scott College of Business at Indiana State University. He earned his Ph.D. in Operations Management from Indiana University's Kelley School of Business. His teaching interests are in operations management, with a focus on the application of technology to process analysis and improvement. His research interests include process simulation, quality management and improvement, manufacturing scheduling, and information systems management. He is a member of the Decision Sciences Institute, American Society for Quality, Production and Operations Management Society, and APICS. His work has been published in multiple outlets including the Quality Management Journal, International Journal of Production Economics, Journal of the Academy of Business Education, and Journal of Network and Systems Management.

\section{REFERENCES}

1. ${ }^{1}$ Bjorlin, C. (2008, November 5). In SAP vs. Oracle war, promise of Fusion puts Oracle stratey on top, report says. Retrieved April 10, 2009, from SAP News: http://searchsap.techtarget.com/news/article/0,289142,sid21 gci1337792,00.html

2. $\quad{ }_{2}^{2}$ Bjorlin, C. (2008, July 9). SAP, Oracle expand vertical functionality in ERP software systems. Retrieved April 17, 2009, from Manufacturing ERP News: http://searchmanufacturingerp.techtarget.com/news/article/0,289142,sid193_gci1326111,00.html

3. ${ }^{3}$ Bjorlin, C. (2009, January 6). Two midmarket CIOs choose SAP over Oracle, others for ERP software. Retrieved April 16, 2009, from SAP News: http://searchsap.techtarget.com/news/article/0,289142,sid21_gci1344176,00.html 
4. Blau, J. (2005, November 9). SAP CEO: Learning to live with co-opetition. Retrieved April 15, 2009, from Infoworld: http://www.infoworld.com/d/applications/sap-ceo-learning-live-co-opetition-102

5. Chan, S. (2009, April 21). Oracle's purchase of Sun would pose new challenges for Microsoft. Retrieved April 22, 2009, from The Seattle Times Online: http://seattletimes.nwsource.com $/ \mathrm{html} / \mathrm{microsoft} / 2009091731$ oracleside21.html?syndication=rss

6. deHenry, F. (2006, February 24). Face off: SAP vs. Oracle (The case for Oracle). Retrieved April 17, 2009, from SAP News: http://searchsap.techtarget.com/generic/0,295582,sid21_gci1166780,00.html

7. Franke, J. (2007, September 12). SAP snags big win over Oracle, thanks to Duet, TCO. Retrieved April 18, 2009, from Manufacturing ERP News: http://searchmanufacturingerp.techtarget.com/news/article/0,289142,sid193 gci1325932,00.html

8. Greenbaum, J. (2006, February 24). Face off: SAP vs. Oracle (The case for SAP). Retrieved April 17, 2009, from SAP News: http://searchsap.techtarget.com/generic/0,295582,sid21_gci1166780,00.html

9. iPhone Firmware 3.0 - Oracle demo its enterprise application. (2009, March). Videocast retrieved April 12, 2009, from YouTube: http://www.youtube.com/watch?v=kb8MoLfYu_I

10. Kolakowski, N. (2009, March 18). SAP goes head-to-head with Oracle over supply chain solutions. Retrieved April 20, 2009, from eWeek: http://www.eweek.com/c/a/Enterprise-Applications/SAP-GoesHeadtoHead-with-Oracle-Over-SupplyChain-Solutions-363283/

11. Oracle support and services for SAP customers. (2009). Retrieved April 22, 2009, from Oracle: http://www.oracle.com/newsletters/sap/service.html

12. PeopleSoft. (2009). Oracle vs. SAP. Retrieved April 22, 2009, from PeopleSoft Planet: http://www.peoplesoft-planet.com/Oracle-vs-SAP.html

13. SAP AG. (2009). Retailer selects SAP over Oracle to support retail and wholesale growth strategy. Retrieved April 17, 2009, from SimplySAP: http://www.simplysap.com/sap-news/sap-articles/retailerselects-sap-over-oracle-support-retail.htm

14. Saran, C. (2008, July 29). Business Intelligence Software: SAP makes waves in water industry. Retrieved April 18, 2009, from ComputerWeekly: http://www.computerweekly.com/Articles/2008/07/29/231662/sapmakes-waves-in-the-water-industy.htm

15. Technology Partners: Oracle and SAP. (2009). Retrieved April 16, 2009, from SAP Global: http://www.sap.com/ecosystem/customers/directories/technology/oracle/index.epx

16. Tillman, K., \& Grady, A. (2007, July 16). Companies choose Oracle over SAP to lower costs and get better results. Retrieved April 19, 2009, from Oracle Press Release: http://www.oracle.com/corporate/press/2007_jul/oracle-sap-momentum-jul.html

17. ${ }^{1}$ Wailgum, T. (2008, November 17). Oracle vs. SAP: Who has the better ERP apps strategy. Retrieved April 17, 2009, from ITworld: http://www.itworld.com/software/57925/oracle-vs-sap-who-has-better-erpapps-strategy

18. ${ }^{2}$ Wailgum, T. (2008, June 18). SAP skills shortage ultimately hurts company. Retrieved April 18, 2009, from ITworld: http://www.itworld.com/print/53149

19. Wang, R., \& Hamerman, P. D. (2008, November 11). Topic Overview: Enterprise Apps Vendor Selection. Forrester Research , pp. 2-9.

20. Westervelt, R., \& Brunelli, M. (2006, March 6). SAP vs. Oracle: Users speak out. Retrieved April 18, 2009, from SAP News: http://searchsap.techtarget.com/news/article/0,289142,sid21_gci1170970,00.html 
NOTES 